\title{
Exploring Métis health, spirituality and well-being: a patient-oriented community-based qualitative study with the Métis Nation of Alberta - Region 3
}

\author{
Carla S. Ginn RN PhD, Craig W.C. Ginn PhD, Lawrence Gervais, Judy Gentes, \\ Doreen Dumont Vaness Bergum, Noelle Rees, Travis Ronald, Tom Doupé, Ashley Camponi
}

\section{Abstract}

Background: There is a lack of Métis-guided participatory research on factors that contribute to individual, family and community wellbeing, such as developing social support and engaging in cultural, social and historical processes for healing and health. The purpose of this study was to explore links among health, spirituality and well-being within the Métis Nation of Alberta (MNA) - Region 3.

Methods: In the largest of 12 MNA - Region 3 communities, together with a working group of 9 community members, informal and elected leaders, and an Elder, we codeveloped a qualitative structured survey exploring health, spirituality and well-being. Following face-to-face distribution of the paper survey to community members (February to March 2019), we engaged with 7 working group members in coding and theme development. Results were shared with the community.

Results: Thirty-one community members requested surveys, with 29 participants aged 28-80 years (mean 54.77 yr, standard deviation $15.31 \mathrm{yr}$ ) completing the surveys (94\% completion rate). Six participants were in the working group that codeveloped the survey. An overarching theme of connection and 4 corresponding subthemes were identified; central to well-being was maintaining connection and balance in mental, emotional, spiritual and physical aspects of health. Connection to Métis ancestry required understanding identity; connection to community involved feeling at home; connection to land included belonging; and connection to tradition encompassed blending of cultures.

Interpretation: Connection among ancestry, land, community and tradition contributed to well-being in our sample. Under the direction of each MNA region, exploration of health, spirituality and well-being with the use of our survey could be considered in community-specific Métis-guided ways across the remaining 5 MNA regions; the survey may also be of use to other provincial bodies in the Métis Nation.

Plain language summary: There is much information about colonization, loss and marginalization among Métis people in Canada; however, more community-based research is needed about building community, developing social support, and engaging in cultural, social and historical practices for healing and health. In this study, we explored links between health, spirituality and wellbeing within the Métis Nation of Alberta (MNA) - Region 3. We met with elected MNA - Region 3 leaders to discuss potential study topics and discussed ways to go about the study. With a working group of community members, informal and elected leaders, and an Elder from MNA - Region 3, we codeveloped a survey and distributed it face to face in the largest of the 12 MNA - Region 3 communities (Calgary). We analyzed the survey results together and identified a main theme of connection: connection to Métis ancestry, to community, to land and to tradition. We plan to collaborate with our working group to codistribute, coanalyze and codisseminate the survey in community-specific ways throughout the other MNA - Region 3 communities to increase understanding about health, spirituality and well-being.

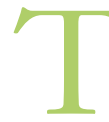
here are 3 groups of Indigenous peoples in Canada: First Nations, Métis and Inuit. "Métis" means a person who self-identifies as Métis, is distinct from other Indigenous peoples, is of historic Métis Nation ancestry and is accepted by the Métis Nation. ${ }^{1}$ In 1870, Métis leader Louis Riel negotiated Manitoba's entrance into Canadian confederation and was subsequently exiled. Later, Métis people in Saskatchewan asked Riel to assist in obtaining titles for their land, and, when peaceful negotiations failed, Riel and Gabriel Dumont (a peacemaker who assisted First Nations people and who spoke Cree, Ojibwa, Sioux and Blackfoot fluently) waged a resistance against the Canadian government. ${ }^{2}$ Peaking at Batoche, Saskatchewan, in 1885, this struggle resulted in a battle in which 5000 Canadian soldiers

Competing interests: None declared.

This article has been peer reviewed.

Correspondence to: Carla Ginn, cginn@ucalgary.ca

CMAJ Open 2021. DOI:10.9778/cmajo.20200018 
fought 400 Métis and Cree. Métis families were scattered and forced into hiding. ${ }^{2,3}$ Riel gave himself up, received an unfair trial and was executed; many Métis leaders were jailed. ${ }^{2}$

In the late 19th and 20th centuries, further intergenerational trauma resulted from the forced transfer of Indigenous children ( $9 \%$ of whom were Métis) into residential schools, as well as the "Sixties Scoop," in which thousands of Indigenous children were taken into foster care and adopted, in most cases by non-Indigenous families. ${ }^{3-6}$ Today, Indigenous children in foster care are among the most vulnerable children in Canada. ${ }^{7}$ Currently, $7 \%$ of children in Canada are Indigenous, yet Indigenous children account for $52 \%$ of children less than age 14 in care. ${ }^{8}$ In addition, $10 \%$ of children overall in Canada live in low-income families; this proportion increases to $50 \%$ for Indigenous children. ${ }^{9,10}$ Métis people continue to experience questioning of Indigenous identity, changes to traditional ways of life and a lack of legal rights. ${ }^{11}$

The Truth and Reconciliation Commission of Canada Calls to Action indicate that research arising from within First Nations, Métis and Inuit communities can promote equity and justice. ${ }^{12}$ Much research regarding detrimental effects of colonialism exists, but there is a lack of Métisguided participatory research on factors that contribute to individual, family and community well-being, such as developing social support and engaging in cultural, social and historical processes for healing and health. ${ }^{13,14}$ In addition, there is an urgent need for research contributing to policy development to increase health equity for Indigenous people. ${ }^{15}$

The objective of this study was to explore links among health, spirituality and well-being within the Métis Nation of Alberta (MNA) - Region 3. Our research question was: "What are the ways that health, spirituality and well-being are connected?"

\section{Methods}

\section{Setting}

Alberta has the highest number of Métis people in Canada. More than 114375 self-identified and 42000 registered Métis people live within $6 \mathrm{MNA}$ regions. ${ }^{16}$ This patient-oriented community-based study took place in Calgary, the largest of the 12 MNA - Region 3 communities.

\section{Design}

The purpose of this patient-oriented community-based qualitative study was to develop and administer a structured survey exploring links among health, well-being and spirituality in MNA - Region 3. Following Tri-Council Policy Statement-2 guidelines, ${ }^{17}$ we engaged respectfully with community members, informal and elected leaders, and an Elder of the region for the study.

Three theoretical frameworks grounded our research. First, we incorporated Indigenous ways of knowing, a belief in the connectedness of all things with transmission from generation to generation. ${ }^{18,19}$

Second, we used the principles of participatory action research, influenced by Lewin, ${ }^{20}$ who questioned the perma- nence of social change without community involvement, emphasizing the harmful effects of colonialism. The concept of participatory-action research was developed by Freire ${ }^{21}$ (placing those being researched at the centre of knowledge translation) and Fals-Borda ${ }^{22}$ (assisting grassroots groups to incorporate local knowledge into change).

Finally, we framed the study using the International Association for Public Participation Spectrum of Public Participation (https://iap2canada.ca/) (Figure 1). We collaborated with MNA Region 3 community members, informal and elected leaders, and an Elder to engage in meaningful Métis-led research in which they eventually became the decision-makers regarding survey development, distribution, analysis and dissemination (Figure 1).

\section{Participants}

Our target population was the 14000 registered MNA members 18 years of age or more residing in MNA - Region 3, specifically those living in Calgary and surrounding area (6300 members). We excluded those who self-identified as Métis but were not registered by the MNA.

\section{Data sources and collection}

The structured qualitative survey that was developed included all ideas and areas of interest brought forward by 9 working group members (community members, informal and elected leaders, and an Elder of MNA - Region 3) from November 2018 to January 2019, in conjunction with 2 authors (C.S.G. and C.W.C.G.). More details on community and patient involvement in the development of the survey are provided in the patient engagement section.

The survey was approved by the elected leaders of MNA Region 3 for distribution in early February 2019. The survey was paper-based; it contained checkboxes for areas of interest on the first page and 5 open-ended questions spread over 5 pages, with space for writing ideas and answers (Appendix 1, available at www.cmajopen.ca/content/9/2/E451/suppl/DC1).

As recommended by elected community leaders, data collection occurred face to face at $2 \mathrm{MNA}$ - Region 3 community "mixers" (monthly social events), in February and March 2019. Two authors (C.S.G. and C.W.C.G.) introduced the study, described the process of survey development, reviewed informed consent procedures and invited interested people aged 19 or more to participate. Questions were discussed, written consent was acquired, and surveys were completed individually or in groups, as per participant preference, at tables scattered throughout the room.

\section{Patient engagement}

Our research was guided by the National Aboriginal Health Organization principles of ethical Métis research, including building reciprocal relationships, respecting practices and protocols, recognizing diversity, researching with outcomes of relevance, and understanding relevant Métis history including straddled worldviews. ${ }^{23}$ Crucial to our research was the involvement of author C.W.C.G., a member of MNA Region 3 who had explored interest in engagement in research over the previous few years with community leaders. 


\section{IAP2'S PUBLIC PARTICIPATION SPECTRUM}

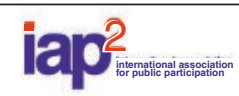

The IAP2 Federation has developed the Spectrum to help groups define the public's role in any public participation process. The IAP2 Spectrum is quickly becoming an international standard.

\begin{tabular}{|c|c|c|c|c|c|}
\hline & INCREASING IMPAC & ON THE DECISION & INVOLVE & COLLABORATE & EMPOWER \\
\hline 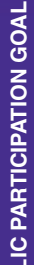 & $\begin{array}{l}\text { To provide the public } \\
\text { with balanced and } \\
\text { objective information } \\
\text { to assist them in } \\
\text { understanding the } \\
\text { problem, alternatives, } \\
\text { opportunities and/or } \\
\text { solutions }\end{array}$ & $\begin{array}{l}\text { To obtain public } \\
\text { feedback on analysis, } \\
\text { alternatives and/or } \\
\text { decisions. }\end{array}$ & $\begin{array}{l}\text { To work directly with } \\
\text { the public throughout } \\
\text { the process to ensure } \\
\text { that public concerns } \\
\text { and aspirations are } \\
\text { consistently } \\
\text { understood and } \\
\text { considered. }\end{array}$ & $\begin{array}{l}\text { To partner with the } \\
\text { public in each aspect } \\
\text { of the decision } \\
\text { including the } \\
\text { development of } \\
\text { alternatives and the } \\
\text { identification of the } \\
\text { preferred solution. }\end{array}$ & $\begin{array}{l}\text { To place final } \\
\text { decision making in } \\
\text { the hands of the } \\
\text { public. }\end{array}$ \\
\hline 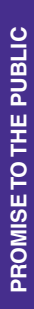 & $\begin{array}{l}\text { We will keep you } \\
\text { informed. }\end{array}$ & $\begin{array}{l}\text { We will keep you } \\
\text { informed, listen to and } \\
\text { acknowledge concerns } \\
\text { and aspirations, and } \\
\text { provide feedback } \\
\text { on how public input } \\
\text { influenced the } \\
\text { decision. We will seek } \\
\text { your feedback on } \\
\text { drafts and proposals. }\end{array}$ & $\begin{array}{l}\text { We will work with you } \\
\text { to ensure that your } \\
\text { concerns and } \\
\text { aspirations are directly } \\
\text { reflected in the } \\
\text { alternatives developed } \\
\text { and provide feedback } \\
\text { on how public input } \\
\text { influenced the } \\
\text { decision. }\end{array}$ & $\begin{array}{l}\text { We will work together } \\
\text { with you to formulate } \\
\text { solutions and } \\
\text { incorporate your } \\
\text { advice and } \\
\text { recommendations } \\
\text { into the decisions to } \\
\text { the maximum extent } \\
\text { possible. }\end{array}$ & $\begin{array}{l}\text { We will implement } \\
\text { what you decide. }\end{array}$ \\
\hline
\end{tabular}

Figure 1: International Association for Public Participation (IAP $\left.{ }^{2}\right)$ Spectrum of Public Participation. @ International Association for Public Participation (www.iap2.org). Reproduced with permission.

We formally met with the elected leaders of MNA Region 3 in April 2018 to inquire about the possibility of a study, potential topics and how to conduct the research. They suggested exploring issues surrounding health, spirituality and well-being, and recruiting volunteers through community mixers, to which all MNA - Region 3 members are invited.

At an October 2018 mixer, all MNA - Region 3 members over the age of 18 were invited to participate in survey development through working groups. During the first working group meeting, in November 2018, 7 participants discussed meaningful survey ideas and questions to explore links among health, spirituality and well-being. Six participants attended a second working group in January 2019, at which the draft survey was completed ( 3 participants from the first working group were absent, and 2 new participants attended). At both working group meetings, a community member (A.C.) and research team member (C.S.G.) took notes while attendees discussed areas of importance for survey inclusion regarding health, spirituality and well-being.

Working group members also participated in data analysis; those who participated in data analysis are coauthors (L.G., J.G., D.D.V.B., N.R., T.R., T.D. and A.C.). As well, working group members participated in dissemination and affirmation of the initial findings and final study results at a May 2019 mixer and an October 2019 mixer, respectively.
After data collection, the survey was revised by a survey design expert (a research associate in the Nursing Research Office, Faculty of Nursing, University of Calgary) and was subsequently approved by MNA - Region 3 elected leaders for codistribution in community-specific ways throughout the remaining MNA - Region 3 communities.

\section{Data analysis}

We de-identified, scanned and transcribed the surveys. Working group members who had codeveloped the survey were invited to participate in data analysis, and 7 volunteered.

In April 2019, we engaged with this working group of community members, informal and elected leaders, and an Elder in participatory coding and theme development. ${ }^{24,25}$ All survey data were laid out on a large table on separately printed pieces of paper. Participants picked up written statements that held the most meaning to them, discussed why and placed them in piles, developing themes. An overarching theme and subthemes were identified by working group members.

Throughout the process of data analysis, stories were shared as written statements brought up memories and additional ideas for themes. No limit was placed on the amount of statements that could be chosen, and no limit was placed on the number of themes. Differences of opinion as to the most salient content and themes were resolved through group discussion. 
Two authors (C.S.G. and C.W.C.G.) drafted an initial manuscript, which was disseminated to the working group for further insight, questions and validation. This data analysis process and initial results were discussed and affirmed at an MNA - Region 3 mixer in May 2019. At an October 2019 mixer, working group members codisseminated the study results, which were discussed and affirmed within the larger community.

\section{Ethics approval}

We obtained ethics approval from the University of Calgary Conjoint Health Research Ethics Board (REB18-0433).

\section{Results}

Thirty-one community members requested surveys, and 29 participants completed surveys (completion rate $94 \%$ ). Of the 29 surveys completed, 6 were from participants who had been in the working group that codeveloped the survey. Participants ranged in age from 28 to 80 years (mean $54.77 \mathrm{yr}$, standard deviation $15.31 \mathrm{yr}$ ).

An overarching theme of connection and 4 corresponding subthemes were identified: connection to Métis ancestry, connection to community, connection to land and connection to tradition (Table 1).

Table 1 (part 1 of 3): Quotes supporting primary theme and subthemes

Theme; subtheme

Representative quote

Connection

I come to you today to share the spirit, wisdom and culture of our Métis heritage.... In the 1940 s and the '50s, it was against the law to speak our Michif language, against the law to gather as a family or have community dances. Every summer in July, my parents would place willows and a canvas over the box of the truck and load their family of 10 . Clothing, bedding, food, cooking supplies, and we headed off to Lac Ste. Anne pilgrimage. ... We were taught to pray through the love of our parents. This was also a time for friends and relatives to visit and share their language, fish, dried meat, bannock and stew. Loving times with people of Métis gathered.... They would walk for miles to be with their own people.... I have memories and visions of my parents walking in the healing waters of Lac Ste. Anne. The spirit of Lac Ste. Anne will remain in my heart forever. No one can take the spirit of God from us. I have shared Lac Ste. Anne with my children and my grandchildren. (Doreen Dumont Vaness Bergum, Elder $†$ )

Our Creator, Great Spirit and Lord, is viewed, pondered, worshipped by all.

Where for art Thou? Everywhere, in everything.

Tho far beyond words I have another name for the way in which we are never alone.

Thee Orchestrator of Infinity rhymes with Divinity, while embracing every heartbeat of every creature Poetry in motion, Loves our devotion. (Travis Ronald*)

How are [health, spirituality and well-being] separated — one cannot be without the others - spirituality is the nucleus or focus which keeps all others in balance and sync. (Participant C-004)

I find if you are not of a sound mind, then your body will never "fully" be healthy. Our health starts internally and mentally. (Participant C-023)

When my spirit loses a sense of purpose, lack of love, too much stress, life distractions, then my health starts to decline and my whole sense of well-being suffers adversely. We must feed all: mind, body, soul, spirit and love! (Participant C-013)

Take medicine and food that you grow. Be happy and don't dwell on negative people. Walk away lonely from people [who] will hurt you. (Participant C-001)

I learned of the medicine circle many years ago. It is an Aboriginal approach to the way that there are 4 directions in life - North, South, East and West. There are also 4 major categories for humans to consider and prioritize - mental, emotional, spiritual, and physical. I have been told and consider it to be a very valuable way of looking at things. ... Balance all 4 of these areas equally. If you are too emotional or too spiritual, your other areas will be less fulfilled, causing you to be unbalanced. Just as the wind is under both wings of every bird, there is a natural balance to admire and to strive to achieve in your own ingredients of life. (Participant C-020)

Most people [who] have addictions are hurting inside, and they are trying to fix it. (Participant C-008)

Addiction and spirituality - both are very deep in nature and effect. One is dangerous, and the other is strengthening. In other words, opposites yet competing. Spirituality and cultural history as a tool for healing. One needs something to believe in. To rely on both in an ongoing nature. Something that should deepen over the years as one grows older and more dependent on beliefs as their physical activity decreases and needs something to replace it. (Participant C-015)

A need for continued support for recovering alcoholism and drug abuse. Need a place to go for support groups. List of people to call when think I am going to relapse. (Participant C-030)

When I am not in touch with my spirit, I feel unwell. (Participant C-012)

When you are healthy spiritually, you are usually healthy. (Participant C-011)

Totally connected, the difficulty is Western culture asks us to work and live, leaving emotions and spirituality out of the picture; then we suffer consequences of mental health issues. (Participant C-002) 
Table 1 (part 2 of 3): Quotes supporting primary theme and subthemes

Theme; subtheme

Representative quote

Connection to Métis ancestry

Grounded! Always have known who I was and my family and Métis culture. (Participant C-022)

My grandfather hid from our family that we were Métis because of the prejudice that existed against Métis back in the 1920s, when he started his family near Winnipeg, Manitoba. I didn't find out that I was Métis until I did some research into my family tree in 2003. It took me over a year on my own to put together the genealogy, but the family history and stories I found to be amazing and explained a lot to me of who I was and why I am the way I am. (Participant C-010)

Once we learnt about our Métis status, we have been learning, trying to understand why my parents never talked about it. My mom, who is now nearly 90 years old, has started to tell us a bit more. (Participant C-006)

The more I share my identity, the more others are accepting of me. The more I hide my identity, the more untrusting (confused) people can be of me. (Participant C-014)

Protecting yourself from racist people. You put up a shield of armour to protect your ... hearing, sight and heart. (Participant C-003)

Though some would say that Métis people can usually hide their identity, this hiding does nothing to promote health, spirituality and well-being. [As I am] Métis, lots of people tend to believe that I am not a productive, worthwhile human being. Sometimes it is easier to fall into the trap of what people expect instead of standing up for what I truly believe and what I really am! (Participant C-030)

They tell me to say I am French, as the Métis are sometimes looked down on, but I am who I am. (Participant C-001)

If the medical community is aware that I am Aboriginal, there is obvious discrimination. (Participant C-021)

If I hide my Métis identity, my spirit and my health suffer. If I share my Métis identity with mainstream society, I suffer racism. (Participant C-002)

Connection to I believe that addressing the wholeness of a person and of a community is the only way that we can community address root causes of the intergenerational and direct trauma that cause Indigenous people to remain on the margins of society. These traumas, combined with systemic racism, trap us in lifestyles where our choices become very limited and the cycles of hopelessness are perpetuated. Our culture and language are who we are and who we always have been. They are our spirituality, our religion and our governance. They are integral to our ability to heal, because without them neither the individual nor the community can reclaim our wholeness. Until we are whole, we cannot see other than what we have already seen. (Participant C-017)

I am highly interested in how past trauma can be passed down to younger generations and how we can break the cycle of addiction/abuse. (Participant C-023)

[Health, spirituality, well-being] are all connected through my community. (Participant C-021)

Once I knew I was Métis and met more Métis, I felt like I had come home. (Participant C-008)

The Métis [people are] very hard working and they are very productive in the community. Lots of the Métis people start companies and contribute to society. (Participant C-030)

I am very new to the community, so being part of this community really brings me joy, which helps with my well-being. (Participant C-016)

Connection to land We belong to the land, and without our connection to the land and nature we suffer. We are community spirited, and without our kinship we are lost. Strong culture = strong spirit. (Participant C-002)

I have strong feelings that we as a nation of Métis people need to reconnect with the land to be selfsufficient and live off the land to find better health nutritionally but also mentally, and the work to do so creates physical health. Land claims - I hope that as a nation we can get our land back so we can continue to become more self-sufficient and provide healthy food for ourselves. (Participant C-019)

[I] want to see the harvesting rights given to the Métis the same as the First Nations. Grandmother was robbed of her land by the government. (Participant C-030)

How much more beneficial is it with sustainable harvesting to use rod and line? My ancestors were scouts and interpreters - I am honoured with the example they have left for me to follow. (Participant C-004)

Body movement, breath work, connection to land, prayer, smudge, healthy food and being connected to heart is ... a major key in my current health. (Participant C-031)

I go to church most weeks, and I believe this helps keep a person happier through the good times and the bad times that this life can dish out. My Catholic religion helps me with spirituality, and my Métis background helps me to find this spirituality in the great outdoors out in the environment and wilderness. (Participant C-010) 
Table 1 (part 3 of 3): Quotes supporting primary theme and subthemes

\begin{tabular}{|c|c|}
\hline Theme; subtheme & Representative quote \\
\hline \multirow[t]{12}{*}{$\begin{array}{l}\text { Connection to } \\
\text { tradition }\end{array}$} & $\begin{array}{l}\text { Can we teach cultural history and practices to foster spirituality in a way [that provides] "soul food" for one's spirit? } \\
\text { If we have gaps in our cultural history and identity, can we feel spiritually whole and fulfilled? Passing on Métis } \\
\text { traditions and culture to younger generations - [I] feel this is important to foster a younger, healthy, thriving } \\
\text { Métis generation. This can take [place] through numerous modalities: music, art, song, games, etc. representing } \\
\text { traditional cultures. [It] would be amazing to have cultural "tours" to key Métis historical sites via community bus. } \\
\text { Guided, informative and a journey of healing, understanding and cultural immersion ... "retreats" - spiritual, } \\
\text { cultural, educational - that can be informative, experiential and healing as a collective. (Participant C-013) }\end{array}$ \\
\hline & $\begin{array}{l}\text { I believe having a connection with a higher power gives people a reason to live and a sense of moral } \\
\text { responsibility. Our general well-being is constantly affected by our daily decision-making, and our daily } \\
\text { decision-making can be directly linked to our spirituality or lack thereof. (Participant C-019) }\end{array}$ \\
\hline & When I feel spiritually connected, I feel better, physically look better and feel grounded. (Participant C-014) \\
\hline & $\begin{array}{l}\text { I walk with the Lord ... coming to know Jesus as my Lord and allowing him to be part of my life. He healed } \\
\text { my mind, body and soul. (Participant C-008) }\end{array}$ \\
\hline & My Catholic religion provides me with my God, and my God is the Creator. (Participant C-010) \\
\hline & $\begin{array}{l}\text { How best can blending different cultures and spiritual practices be bridged to honour and respect both? } \\
\text { (Participant C-013) }\end{array}$ \\
\hline & $\begin{array}{l}\text { Smudging is good and helps me feel good. Also sweats, praying and keeping in touch with my spirituality } \\
\text { helps me maintain a good perspective on life. (Participant C-011) }\end{array}$ \\
\hline & $\begin{array}{l}\text { I pray to many gods: [Jesus Christ], Creator, Quan Yin, Buddha, Angel Spirits, Animal Totems. [It] gives a } \\
\text { greater sense of totality and connectedness to all having something to offer. I pray, drum, smudge, practise } \\
\text { yoga, read about angels after life, traditional practices and ... choose what works. (Participant C-013) }\end{array}$ \\
\hline & Became a eucharistic minister in my church and Lac Ste. Anne pilgrimage. (Participant C-003) \\
\hline & Becoming a pipe healer/storyteller. (Participant C-024) \\
\hline & Blending traditional and nontraditional healing and health care. (Participant C-022) \\
\hline & $\begin{array}{l}\text { I attend Christian church and blend my spiritual knowledge and thoughts with the moral ideals and teachings at } \\
\text { the church. If there were a Métis church that imparted traditional teachings, I would attend that. (Participant C-019) }\end{array}$ \\
\hline
\end{tabular}

\section{Connection}

Maintaining connection and balance in mental, emotional, spiritual and physical aspects of health was central to wellbeing for participants. Practices maintaining connection and balance included prayer, exercise, smudging, teaching of the Elders, sharing circles, cultural field trips, Lac Ste. Anne pilgrimages, learning about history, nutrition, having patience, quitting drinking, open-mindedness, self-control and selfassessment. Addiction and spirituality were described as powerful opposites with deep effects.

\section{Connection to Métis ancestry}

Some participants had always been aware of their Métis identity, whereas discovery of Métis ancestry happened later for others. Because of the residential schools and the Sixties Scoop, many families hid their Métis identity. Historical and ongoing tension surrounding personal disclosure of Métis identity existed for many participants. In relation to Métis ancestry, experiences of racism had occurred in conjunction with experiences of belonging.

\section{Connection to community}

Health, spirituality and well-being were all connected to Métis identity and community. Participants identified intergenerational effects of trauma on individual and community healing and wholeness, with much emphasis on breaking cycles of addiction and violence. Participants wrote about hopelessness being replaced with healing and wholeness through connection with culture, language, spirituality, religion and selfgovernance at the individual and community level.

\section{Connection to land}

Connection to land and community contributed to health and well-being but had been interrupted. Fostering connection to land included passing on historical knowledge and traditions through music, art, games, jigging (a traditional dance usually accompanied by the fiddle), smudging and being connected to heart in the context of community.

\section{Connection to tradition}

Connection to Indigenous and Roman Catholic traditions of wellness and healing included actions, practices and rituals. Participants wrote about respecting all spiritual practices, describing how spirituality and identity were deeply connected with Métis cultural traditions.

\section{Interpretation}

In this community-based participatory qualitative study in which we engaged with members, informal and elected leaders, 
and an Elder in the largest MNA - Region 3 community to codevelop, coanalyze and codisseminate a survey exploring health, spirituality, and well-being, our participants described the importance of telling their stories, sharing who they are, and pursuing well-being for themselves and their community. An overarching theme of connection emerged, to Métis ancestry, to community, to land and to tradition.

Our findings of connection coincide with the National Aboriginal Health Organization's historical, current and future determinants of Métis health. ${ }^{26}$ Historical determinants were colonialism, racism, marginalization, lack of Métis rights and lack of Métis land, and determinants moving forward are loss of culture, and Métis knowledge, language and spirituality. Other current and future determinants include selfdetermination, resiliency, healing, resurgency and education. ${ }^{27}$

Some participants in our study had always known they were Métis, whereas others discovered it later in life; tension between hiding and revealing identity was common. Passing as "White" had been used as a survival tactic and could contribute to decreased connection with spirituality. ${ }^{28}$ Participants noted that hiding or "passing" was not conducive to well-being. Findings from a 2018 federal government emergency meeting regarding the high number of Indigenous children in care identified ignorance among child welfare authorities about who the Métis people are as a key factor. ${ }^{8}$ Métis children are overrepresented and unrecognized in Canada's child welfare systems, and Métis people are more likely than non-Indigenous Canadians to experience health and social challenges, with resulting social work involvement. ${ }^{29}$

Health, spirituality and well-being occur in community, and, although our participants described individual and community wholeness and healing, they also described effects of trauma and the need to break intergenerational cycles of addiction and abuse. Impacts of residential school on former attendees and subsequent generations include poorer physical health, increased rates of chronic and infectious disease, mental distress, depression, addiction, substance misuse, increased stress and suicidal behaviour; past collective trauma affects current health. ${ }^{26,30}$ Managing intergenerational trauma, resultant health disparities and ongoing structural violence requires protective buffers including decolonizing strategies such as self-determination and selfgovernance, identity formation such as cultural engagement and culturally adapted interventions that address historical trauma. ${ }^{31}$

On June 27, 2019, the MNA signed the first agreement between a Métis Nation and the Government of Canada, with a clearly defined process to implement Métis jurisdiction in core areas of self-government. ${ }^{32}$ Participants in our study described wanting to reconnect with land and how they were seeking reparation for wrongs done in their families and communities. The Canadian government has moved slowly regarding Métis land claims. ${ }^{33}$ Each generation of Métis people has experienced challenges, with resultant resilience, determination, independence and a strong, adaptable work ethic; current challenges include reconnecting with Métis identity, culture and tradition. ${ }^{34}$

Participants attributed well-being to connection with spirituality, including Indigenous and Roman Catholic traditions of wellness and healing. Some practised Roman Catholic traditions, viewing God as Creator, others blended Indigenous traditions with Roman Catholic beliefs, and some included more than 1 religious tradition in their actions, practices and rituals. This hybridity was evident in the life of Louis Riel, a devout Roman Catholic who also embraced Indigenous spirituality. ${ }^{28}$ Participants emphasized honouring and respecting different cultures and spiritual practices, including praying, smudging, sweats and picking sacred plants used as medicines.

Maintaining connection to Métis ancestry, to community, to land and to tradition presents a potential for increased health and well-being, and healing intergenerational trauma. Engaging in community pilgrimages to sacred sites and cultural tours to historical sites may contribute to individual, family and community health, spirituality and well-being. In addition, communities may benefit from meeting together regularly to participate in meaningful activities, focused on balancing mental, emotional, spiritual and physical health.

This survey was approved by the elected leaders of MNA Region 3 for face-to-face codistribution in communityspecific ways throughout the 12 communities of MNA Region 3. Under the direction of each MNA region, further exploration of health, spirituality and well-being by means of Métis-guided community-based research specific to each community could be considered across the 5 other MNA regions; other provincial bodies in the Métis Nation may also find the survey of use.

\section{Limitations}

Limitations of our study include a small sample in 1 geographic area; therefore, our findings may not be generalizable to the entire MNA - Region 3 or beyond. We collected only date of birth from participants, which limited our ability to describe their demographic characteristics. We did not pretest individual questions within the survey or the survey as a whole. Completing the survey by hand was labour intensive and may have limited responses. In addition, response bias may have occurred through distribution at community mixers. Some people may have preferred the anonymity and convenience of electronic distribution, which may have affected their decision to participate or the quality of their responses. Distribution only to those who attended the mixers may have resulted in the engagement of a different group than those who did not attend (e.g., older community members), which also may have resulted in response bias. Finally, we were unable to calculate a response rate, as the number of members attending each mixer was not recorded; this may have resulted in response bias.

\section{Lessons learned from patient engagement}

Engaging the MNA - Region 3 community in this patientoriented community-based qualitative study in codeveloping, coanalyzing and codisseminating results of the survey presented an opportunity for increased individual and community knowledge regarding Métis identity and ancestry, health, spirituality and well-being; increased research capacity within MNA - Region 3; increased collaboration in community-led 
identification of priorities for community-initiated funding and policy development; and contributed to increased understanding regarding individual, family and community wellbeing within MNA - Region 3. Participants described the importance of telling their stories, sharing who they are and persisting in pursuing well-being for themselves and their communities.

\section{Conclusion}

In the largest of the $12 \mathrm{MNA}$ - Region 3 communities, connection emerged as the overarching theme of a qualitative structured survey exploring health, spirituality and well-being. Connection to Métis ancestry, connection to community, connection to land and connection to tradition contributed to healing and well-being. This research will contribute to opportunities for further research with the survey in collaboration with other MNA regions, in Métis-guided, patientoriented, community-specific ways. The findings have the potential for improving patient outcomes by increasing health care providers' knowledge of who Métis people are.

\section{References}

1. Métis registration guide. Ottawa: Métis National Council; 2011.

2. Teillet J. The North-West is our mother: the story of Louis Riel's people, the Métis nation. Toronto: Harper Collins; 2019:3-376.

3. Podruchny C, Thistle JA. A geography of blood: uncovering the hidden histories of Metis people in Canada. In: Lehmkuhl U, Lusebrink HJ, McFalls L, editors. Spaces of difference: conflicts and cohabitation. Münster (Germany): Waxmann; 2016:61-82.

4. What we heard: report of the Métis Nation's engagement with Métis Sixties Scoop survivors. Ottawa: Métis Nation; 2019. Available: https://metissixtie sscoop.ca/wp-content/uploads/2019/11/What-We-Heard-Report-2019.pdf (accessed 2020 Dec. 22)

5. Chartrand LN, Logan TE, Daniels JD. Métis history and experience and residential schools in Canada. Ottawa: Aboriginal Healing Foundation; 2006:115.

6. Spencer DC. Extraction and pulverization: a narrative analysis of Canada scoop survivors. Settl Colon Stud 2017;7:57-71.

7. Tait CL, Henry R, Walker RL. Child welfare: a social determinant of health for Canadian First Nations and Métis children. Pimatziwin 2013;11:39-53.

8. A report on children and families together: an emergency meeting on Indigenous child and family services. Ottawa: Indigenous Services Canada; modified 2018 Aug. 31.

9. MacDonald D, Wilson D. Poverty or prosperity: Indigenous children in Canada. Ottawa: Canadian Centre for Policy Alternatives; 2013. Available: www. policyalternatives.ca/sites/default/files/uploads/publications/National\%20Office/ 2013/06/Poverty_or_Prosperity_Indigenous_Children.pdf (accessed 2020 Dec. 22).

10. Aboriginal Peoples in Canada: First Nations people, Métis and Inuit: national housebold survey, 2011 [analytical document]. Cat no 99-011-X2011001. Ottawa: Statistics Canada; 2013.

11. Macdougall B. Land, family and identity: contextualizing Metis bealth and wellbeing. Prince George (BC): National Collaborating Centre for Aboriginal Health; 2017:5-23.

12. Honoring the truth, reconciling for the future: summary of the final report of the Truth and Reconciliation Commission of Canada. Ottawa: Truth and Reconciliation Commission of Canada; 2015:1-382.

13. Kumar MB, Wesche S, McGuire C. Trends in Métis-related health research (1980-2009): identification of research gaps. Can f Public Health 2012;103:23-8.

14. Browne AJ, McDonald H, Elliott D. Urban First Nations health research discussion paper. A report for the First Nations Centre, National Aboriginal Health Organization. Ottawa: National Aboriginal Health Organization; 2009. Available: https://open. library.ubc.ca/cIRcle/collections/facultyresearchandpublications/52383/items/ 1.0084587 (accessed 2020 Dec. 22).

15. McNally M, Martin D. First Nations, Inuit and Métis health: considerations for Canadian health leaders in the wake of the Truth and Reconciliation Commission of Canada report. Healthc Manage Forum 2017;30:117-22.

16. Métis relations: information on Métis history, organizations and legislation. Edmonton: Indigenous Relations, Government of Alberta. Available: https:// www.alberta.ca/metis-relations.aspx (accessed 2021 Apr. 12).

17. Canadian Institutes of Health Research; Natural Sciences and Engineering Research Council of Canada; Social Sciences and Humanities Research Council of Canada. Tri-Council Policy Statement: ethical conduct for research involving humans - TCPS2 2018. Ottawa: Secretariat on Responsible Conduct of Research; 2018. Available: https://ethics.gc.ca/eng/policy-politique_tcps2 -eptc2_2018.html (accessed 2020 Dec. 22).

18. Bastien B. Blackfoot ways of knowing: the worldview of the Siksikaitsitapi. Calgary: University of Calgary Press; 2004:98-148.

19. Hungry Wolf B. The ways of my grandmothers. New York: William Morrow and Company; 1980:137.

20. Lewin K. Action research and minority problems. 7 Soc Issues 1946;2:34-46.

21. Freire P. Pedagogy of the oppressed. 3rd ed. Bloomsbury Publishing Inc.; 2000.

22. Fals-Borda O, Rahman MA. Action and knowledge: breaking the monopoly with participatory action-research. Rugby (UK): Practical Action Publishing; 1991.

23. Principles of ethical Métis research. Ottawa: National Aboriginal Health Organization; 2011.

24. Ginn C, Kulig JC. Participatory action research with a group of urban First Nations grandmothers: decreasing inequities through health promotion. Int Indig Policy 7 2015;6. doi: 10.18584/iipj.2015.6.1.4.

25. Bartlett JG, Iwasaki Y, Gottlieb B, et al. Framework for Aboriginal-guided decolonizing research involving Métis and First Nations persons with diabetes. Soc Sci Med 2007;65:2371-82.

26. Wilk P, Maltby A, Cooke M. Residential schools and the effects on Indigenous health and well-being in Canada: a scoping review. Public Health Rev 2017;38:8.

27. Dyck M. Social determinants of Métis health. Ottawa: National Aboriginal Health Organization; 2008:12.

28. Fiola C. Rekindling the sacred fire: Métis ancestry and Anishinaabe spirituality. Winnipeg: University of Manitoba Press; 2015:14, 31-3.

29. Richardson C. Metis-astute social work: shining the light on some helpful practices. F Indig Soc Dev 2016;6:82-99.

30. Hackett C, Feeny D, Tompa E. Canada's residential school system: measuring the intergenerational impact of familial attendance on health and mental health outcomes. 7 Epidemiol Community Health 2016;70:1096-105.

31. Nutton J, Fast E. Historical trauma, substance use, and indigenous peoples: seven generations of harm from a "big event." Subst Use Misuse 2015;50:839-47.

32. After 90 years, Métis Nation within Alberta achieves federal recognition of its self-government [news release]. Edmonton: Métis Nation of Alberta; 2019 June 27. Available: www.newswire.ca/news-releases/after-90-years-metis-nation -within-alberta-achieves-federal-recognition-of-its-self-government-822768779. html (accessed 2020 Dec. 22).

33. Drake K, Gaudry A. The lands ... belonged to them, once by the Indian title, twice for having defended them ... and thrice for having built and lived on them: the law and politics of Métis title. Osgoode Hall Law f 2017;64:1-52.

34. Kirmayer LJ, Dandeneau S, Marshall E, et al. Toward an ecology of stories: Indigenous perspectives on resilience. In: Ungar $M$, editor. The social ecology of resilience: a bandbook of theory and practice. New York: Springer; 2012:399-414.

Affiliations: Faculty of Nursing (C.S. Ginn) and Department of Classics and Religion (C.W.C. Ginn), University of Calgary; Métis Nation of Alberta - Region 3 (Gervais, Gentes, Bergum, Rees, Ronald, Doupé, Camponi), Calgary, Alta.

Contributors: Carla Ginn and Craig Ginn conceived of and designed the study and drafted the manuscript. All of the authors contributed to survey development, analyzed the data, revised the manuscript critically for important intellectual content, approved the final version to be published and agreed to be accountable for all aspects of the work.

Funding: This study was supported by a research stipend (project 10016275) from the Faculty of Nursing, University of Calgary.

Content licence: This is an Open Access article distributed in accordance with the terms of the Creative Commons Attribution (CC BY-NCND 4.0) licence, which permits use, distribution and reproduction in any medium, provided that the original publication is properly cited, the use is noncommercial (i.e., research or educational use), and no modifications or adaptations are made. See: https://creativecommons.org/licenses/ by-nc-nd/4.0/.

Data sharing: Survey data are available from the corresponding author on request.

Acknowledgements: The authors honour the memory of Marlene Lanz, who was the Regional President of MNA - Region 3 when they began this project and encouraged them to keep moving forward. The authors thank the Elders, leaders and community members who participated in survey development and data collection and analysis.

Supplemental information: For reviewer comments and the original submission of this manuscript, please see www.cmajopen.ca/content/9/2/ E451/suppl/DC1. 